\title{
Self-Directed Learning: It's Role in Learning and Implication for Instruction
}

\author{
Emmanuel N. Ogu, O.P., PhD \\ Dominican University, Samonda, Ibadan Oyo State, Nigeria
}

\begin{abstract}
This paper intends to enlighten educators of adults about some essential elements of self-directed learning and the role of a facilitator. It aims at stimulating thoughts and questions about adult learning. Knowing how adults learn is crucial to educators in facilitating adult learning. The application of strategies for self-directed learning allow adult learners to advance their studies while fulfilling family, work and other commitments (Khiat, H 2015). Developing qualitative processes and programs can enhance self-directed learning. They can provide a conducive learning environment that promotes student growth and facilitates proficiency and professionalism. By developing qualities built around adult appropriate methodologies, teachers can help to enhance student cognition.
\end{abstract}

An expected student response should be the perpetuation of intellectual curiosity and development exhibited by further selfdirectedness behaviours regarding learning.

\section{INTRODUCTION}

\begin{abstract}
A ndragogy is defined as the art and practice of helping adults learn. Mezirow (1985) states that, self-directed learning is the capacity of adults for critical self-reflection and for changing their lives. It is an internal force that compels adult learners to assimilate and internalize information in circumstances they find themselves. While Knowles (1975) said self-directed learning means that individuals take the initiative with or without the help of others in diagnosing their learning needs, formulating learning goals, identifying human and material resources for learning, choosing and implementing appropriate learning strategies and evaluating learning outcomes. Francis (2017) defines self-directed learning as that which gives learners the freedom and autonomy to choose the what, why, how, and where of their learning.
\end{abstract}

Brandt (2020) said that literature reveals four dimensions of self-directed learning:

(a) self-regulation: - the ability to plan, direct and control one's emotions, thoughts, and behaviours during learning tasks.

(b). motivation: the desire to engage in activity that emerges from the inherent enjoyment of an activity or a sense of obligation to engage in a task (Pink, 2009; Ryan \& Deci, 2000).

(c), personal responsibility: a willingness to take full responsibility for one's actions. Learners who demonstrate personal responsibility operate with integrity and act in concordance with clear ethical principles (Battelle for kids, 2019).

(d). autonomy: the ability to recognize available choices and take charge of one's learning, control choices through ongoing reflection and evaluation. Autonomy develops as learners work independently or collaboratively to set goals, plan learning, select resources and learning strategies, and monitor and evaluate progress (Reinders, 2010).

Years of experience as instructor of adults has shown that not all aspects of education help facilitate learning, and that adults are split on the effectiveness of self-directed learning. Adults are more interested in learning subjects that they will actually use in their professional fields or in their personal lives. The whole concept of andragogy is that adults need to be more involved in the learning process, resulting in greater motivation and self-concept. Thus, teachers become more like facilitators orientating and showing their experiences, including mistakes, providing the basis for learning activities. Teachers must remember that learning occurs within each individual as a continual process throughout life.

"Adult learner" is a term used to define any adult engaged in formal study. As defined by the National Center for Education Statistics in 2002, adult learners are also called nontraditional students who meet at least one of these seven criteria: delayed enrollment; part time attendance for at least part of the academic year; works full time; is considered financially independent; has dependents (spouse, children), or is a single parent; and does not have a high school diploma. An adult student is typically a student older than 24 years old who juggles different roles as a student, worker, spouse or parent and has been absent for at least one year from studying in an institution of learning (Howell, 2001; Vande Zauden 2007).

Brookfield's textbook, Understanding and Facilitating Adult Learning, gives the reader comprehensive analyses of principles and effective practices. The facilitation of studyassisting, can make adults understand and act upon the personal, social, occupational, and political environment in which they live. It is an important, exhilarating, and profound activity, both for facilitators and for learners (Brookfield,1986). Adults learn for a range of motives including; life changes such as job loss or, divorce, to enhance a sense of self-worth, or to advancement of one's knowledge, etc. How adults learn can be separated into two distinguishing characteristics: autonomy of direction in the act of learning, and the use of personal experience as a learning 
resource (Brookfield,1986). Knowles (1975) definition has the following elements where students initiate the learning, determine needs, set goals for learning, select strategies and evaluate learning outcomes.

Adult learning theory is known as the science of Andragogy. Andragogy is based on the notion that adults are self-directed learners who are unique based upon their personal experiences. Their need to learn results from their desire to face the challenges they encounter throughout life (Knowles, 1980). Andragogy, is important for trainers' to understand and implement in order to effectively train adult workers in today's world. It is also very important for any country that wants to improve and develop the work force. Andragogy is a process which focuses on the need and experiences of the learner, and involves active learning as opposed to passive absorption of material presented by a teacher.

Later Knowles developed a set of assumptions for the concept of andragogy. These five assumptions include: adults are self-directed learners, adult learners bring a wealth of experience to the educational setting, adults enter educational settings ready to learn, adults are problem- centered in their learning, and adults are best motivated by internal factors (Blondy, 2007). Andragogy as a system of ideas, concepts, and approaches to adult learning has become foundational to the thinking of many adult educators. Speck has proposed the following components of adult learning theory as those most critical to effective professional development design. Adults need real-world applications; adult learning involves egos; adult learners are unique individuals with a wide range of skills and experiences; and the transfer of learning must be facilitated (Speck, 1996).

Adults in their current learning environment: face personal challenges. These challenges are often expressed as having little or no time to complete class assignments due to work pressures, family responsibilities, health, and personal matters that result in fatigue, loss of motivation, and depression. Other challenges are re-engagement to education after several years away and possibly uncertainty about returning.

Brookfield ascertains that, adults tend to seek opportunities for learning. These opportunities are often promoted by life changes, such as marriage, divorce, a job change, job termination, retirement or geographical change. Adults usually want to learn something that will improve their life in some way. Our attention as a healthy open society, which seeks creation, and alteration of our beliefs, values, and relationships, should be helping adults to learn and facilitate self-directed learning. This learning is defined by Knowles as the adult learning theory process with its seven elements include: climate setting; involving learners in mutual planning; involving participants in diagnosing their own needs for learning; involving learners in formulating their learning objectives; involving learners in designing learning plans; helping learners carry out their learning plans; and involving learners in evaluating their learning (Knowles, 1984).
When adults teach and learn in one another's company they find themselves engaging in challenging, passionate, and creative activities; the act of teaching and learning are ways in which we realize our humanity (Brookfield, 1986). It becomes an opportunity for the learner and facilitator to learn from each other. The learner should be encouraged to feel and act responsibly- in planning, doing and assessing the result of their learning activity, and with the relationship with associates, example, peer and tutor.

The role of the facilitator is one of the most important elements in the success of the adult learner. She/he is responsible for monitoring the progress of the students and for communicating all relevant information to the facilitator. Responsibilities of facilitators are to provide equipment, assess troubleshooting, provide instructional support, and administer instruction. They should allow the learner to assume responsibility for presentations and group leadership. They are to guide learners to understand rather than supply them with facts. They must relate theories and concepts to the learners and help them recognize the value of experience in learning. Learning has to be relevant and applicable to their work and other responsibilities. They must be treated as equal and give the opportunity to voice their opinions freely in class. The facilitators need to motivate, and reinforce, retention and transference, to encourage and enhance student performance.

My teaching experience in a university for working adults has shown me what to expect from adult learners, what their responsibilities are, and ultimately what their responsibilities as adult learners will become. The adult education classroom environment is also more suited to the general adult population (even some teens and younger adults), with its emphasis on independent study, flexible class schedules and experience-based curriculum. What their responsibilities include, and ultimately what their responsibilities as adult learners are significantly differ from the traditional 18 to 21 year old college student. There are five specific areas in which adults learn differently than young people. They are: demands of learning, role of the instructor (i.e., anxious), life experiences, purpose for learning, and permanence of learning. Additionally, there are four keys to teaching adults: allow them to direct themselves in the instructional process, integrate new information with previous experiences, and make sure the information is relevant and readily useable for the learner.

Andragogy researchers like Knowles and Brookfield have shown that adult educators can facilitate learning successfully with adult self-directed learners. The adult theory process, eight principles of adult learning, and Speck's adult learning theory all help facilitators create a guideline for teaching adults. The implications for adult learning are described in a number of ways. First of all, adults have their own motivation for learning. These adult learners build on their existing knowledge and experience, fit learning into their own purpose and become engaged in learning. Their purposes for learning 
are related to their real lives and the practices and roles they engage in outside the classroom. Adults drive toward selfdirection in learning and becoming autonomous learners. Adults have the ability to learn about their own learning processes, and can benefit from discussion and reflection on this. They are able to learn how to learn, and reflect and build upon their own experience. Reflective learning is generated when people encounter problems in their real lives and think about ways of resolving them. Reflective learning is unique to each person, since it arises out of their own experience. Reflective learning also enables people to reorganize experience and 'see' situations in new ways. In this way, adult learning is potentially transformative, both personally and socially (NRDC, 2002). These guidelines and others will give facilitators and self-directed learners a range of options for education.

\section{CONCLUSION}

The existence of self-directed learning in adult is well documented. But a lot is still to be desired with the issue of adult learning. We must not allow self-directed learning to become synonymous with self-thought. Those who teach adults will need to be proactive, and by becoming facilitators, advocates, and expositors of the adult learning experience. It is a substantial traditional education that carries potential for greater success. The heightened of this success requires a greater responsibility on the part of the teacher. Adult learners come with precisely defined expectations. However, there are barriers to their learning. The best motivators for adult learners are interest and self -benefit in addition to good / effective facilitators. The role of facilitators in self-directed learning cannot be over emphasized, and the need for them to play this role well is crucial for any nation. It is necessary to carry out a study on self-directed learning with the Open University of Nigeria utilizing survey research methodology.

\section{REFERENCES}

[1] Battelle for kids, (2019). Partnership for $21^{\text {st }}$ century learning: Framework for $21^{\text {st }}$ Century learning definitions. http:// static battelleforkids.org/document/p21/ Framework definitions BFK.pdf.
[2] Blondy, C, A. (2007). Evaluation and Application of Andragogical Assumption to the Adult online Learning Environment. Journal of Interactive Online Learning, 6(2), 1.

[3] Brandt.W.C (2020). Measuring student success skills: A Review of the literature on Self-directed learning. Dover, NH: National center for the improvement of Education Assessment.

[4] Brookfield, S .D. (1986). Understanding and Facilitating Adult Learning. Great Britain. Jossey Boss.

[5] Burge, L. (1988). Beyond Andragogy: Some Explorations for Distance Learning Design Journal of Distance Education, 3(1), 39.

[6] Francis, H. (2017).The Role of Technology in Self-directed learning: A Review. Surrey, England: ACS Center for inspiriting mind.

[7] Khiat,H. (2015). Measuring Self-directed learning: A diagnostic tool for adult learners. Journal Of University teaching and learning Practice Vol 12, Issue 2.

[8] Knowles, M (1975). Self-directed learning: A guide for learners and teachers. New York: Association Press

[9] Knowles, M. (1980). An Andragogical Model of Human Resource Development. The Modern Practice of Adult Education Review, ed. Chicago: Associated Press/Follett.

[10] Knowles, M. (1984). Andragogy in Action. San Francisco: JosseyBass.

[11] Morris, T.H (2019). Self-directed learning: A fundamental competence in a rapidly changing World. International Review of Education, 65, 633-653. Published online by UNESCO Institute for life-long learning and Springer Nature.

[12] National Center for Education Statistics (2002). Statistics of Adult learners on education and public school district finance information. http://nces.ed.gov/programs/coe/2002/analyses/nontraditional/sa01 asp:

[13] National Research and Development Centre for Adult Literacy and Numeracy (2002). Review of Models of Adults learning and their Implications for Literacy and Numeracy. http://www.nrdc.org.uk/projects_details.asp?ProjectID=12

[14] Pink, D (2009). Drive: The Surprising Truth about what motivates us. New York, NY: Riverhead Books.

[15] Pint rich, P (2004). A Conceptual Framework for assessing motivation and self-regulated learning in college students. Educational Psychology Review, 16,385-407

[16] Reinders, H. (2010). Towards classroom pedagogy for learner autonomy: A Framework of independent language learning skills. Australian journal of Teacher Education, 35(5), 39-55.

[17] Ryan, R.M \& Deci, E.L (2000). Intrinsic and Extrinsic motivations: Classic Definitions and New Directions. Contemporary Educational Psychology, 25, 54-67.

[18] Speck, Marsha (Spring 1996). Best Practice in Professional Development for Sustained Educational Change. ERS Spectrum. 